\title{
Antimicrobial Activities of Lactic Acid Bacteria Strains Isolated from Human Breast Milk Against Human Pathogenic Strains
}

\author{
Maryam A. S. Abubakr \\ Department Botany, Faculty of Science, Zawia University, Zawia, Libya \\ Email address: \\ m.abubakr2008@yahoo.com

\section{To cite this article:} \\ Maryam A. S. Abubakr. Antimicrobial Activities of Lactic Acid Bacteria Strains Isolated from Human Breast Milk Against Human \\ Pathogenic Strains. International Journal of Clinical and Developmental Anatomy. Vol. 4, No. 1, 2018, pp. $27-31$. \\ doi: $10.11648 /$ j.ijcda.20180401.14
}

Received: January 10, 2018; Accepted: February 1, 2018; Published: March 2, 2018

\begin{abstract}
This study aims to screen the antimicrobial activity of lactic acid bacteria (LAB) with probiotic properties isolated from human breast milk. A total of six from twenty five $\mathrm{LAB}$ isolated showed clear zone on modified $\mathrm{MRS}-\mathrm{CaCO}_{3}$ agar, catalase negative and Gram positive were considered as LAB. All of the six selected isolates were able to tolerance $\mathrm{pH} 2,0.3 \%$ bile salts for $3 \mathrm{~h}$. The antibacterial properties of these isolates against (Escherichia coli, Bacillus subtilis, Staphylococcus aureus and Salmonella typhimurium) were examined using dual agar overlay and microtiter plates methods. Results found that both the cells and supernatants of six selected LAB isolated showed very good inhibitory activity against the target bacteria. The LAB-HM6 isolate showed the highest inhibitory activity $(32.0 \mathrm{~mm})$ against $S$. aureus followed by LAB-HM5 and LABHM4 (30.3 mm), then LAB-MH1 $(29.3 \mathrm{~mm})$ against $S$. typhimurium. Supernatant LAB-HM5 caused complete inhibition of all target bacteria, LAB-HM3 inhibited S. typhimurium and B. subtilis, and LAB-HM5 also inhibited the growth of $S$. aureus during $72 \mathrm{~h}$ incubation. Thus, these Lab isolates could be considered as potential antimicrobial probiotic strains human pathogens and should be further studied for their human health benefits.
\end{abstract}

Keywords: Human Breast Milk, Lactic Acid Bacteria (LAB), Probiotic Properties, Antimicrobial Activity

\section{Introduction}

Lactic acid bacteria (LAB) LAB is Gram-positive microorganisms, prefer anaerobic conditions LAB is Grampositive microorganisms, prefer anaerobic conditions but are aero tolerant, acid-tolerant, and strictly fermentative. This groups of bacteria is nonpathogenic and save to use with the status of General Recognize as Safe (GRAS), acid resistant, bile tolerant and produce antimicrobial substances, including organic acids and hydrogen peroxide and bacteriocins (biologically active protein). These organisms produce lactic acid as the major end product during the fermentation of carbohydrates. LAB also produce antimicrobial compounds including hydrogen peroxide, $\mathrm{CO}_{2}$, diacetyl, acetaldehyde, Disomers of amino acids, reuterin and bacteriocins, those compounds can be used in many fields such as health care, pharmaceutical and preservation [2,9].

Probiotics are defined as live microorganisms which when administered in adequate amounts confer a health benefit on the host. During last decade, the use of probiotics for human has received increasing attention as scientific evidence continues to accumulate on properties, functionality, and beneficial effects of probiotic bacteria on humans [1]. The search for more new probiotics functional food and beverages and dietary supplements due to rising levels of health consciousness and growing consumer awareness regarding gut health and the concept of preventive health care. It is now well established that some of the infections and disorders in the human body, such as irritable bowel syndrome, inflammatory bowel disease, and antibioticinduced diarrhea, could be due to deficient or compromised intestinal microflora, and probiotics have been considered to be one of the disease control strategies to overcome such disorders. Thus, probiotics have become increasingly considered for use in the food industry [10]. Therefore, the aim of the present study was carried out to isolate of lactic 
acid bacteria (LAB) from human breast milk, as potential probiotic with antimicrobial activity against microorganisms that are pathogenic to human.

\section{Materials and Methods}

\subsection{Collection of Samples}

Samples of breast milk were collected aseptically from three healthy women, within four months of given birth to healthy babies. the nipple and mammary areola of the breast were wiped with $70 \%$ ethanol and a $10 \mathrm{~mL}$ of milk was collected in a sterile test tube using a sterile breast pump.

\subsection{Isolation of Lactic Acid Bacteria (LAB)}

Ten $\mathrm{mL}$ of sample was added to $90 \mathrm{~mL}$ of sterile peptone water $0.1 \%(\mathrm{w} / \mathrm{v})$ and homogenized in the stomacher (Stomacher $^{\circledR} 400$ Circular Seward). Appropriate dilutions were spread plated on de Man, Rogosa and Sharpe (MRS) agar (Oxoid CM0361) plates containing 0.8\% calcium carbonate. Plates were incubated anaerobically in anaerobic jar with AneroGen ${ }^{\mathrm{TM}}$ (Oxoid) at $37^{\circ} \mathrm{C}$ for $48 \mathrm{~h}$. Each of the isolates was tested for catalase activity by placing a drop of $4 \%$ hydrogen peroxide solution on the cells. Immediate formation of bubbles indicated the presence of catalase in the cells. Only those isolates which was catalase-negative was Gram-stained and the morphology was observed using Nikon microscope (Nikon Eclipse 80i) and streaked on MRS agar to obtain pure isolates. All bacterial strains used in this study were maintained in $15 \%$ glycerol stock and stored at $-20^{\circ} \mathrm{C}$. Prior to beginning the experiments, each bacterial strain was sub-cultured at least three times $(1 \%, v / v)$ in MRS broth (Oxoid CM0359) at $37^{\circ} \mathrm{C}$ under anaerobic condition at $24 \mathrm{~h}$ intervals [5].

\subsection{Probiotic Properties of LAB Isolates}

For the determination of probiotic properties of LAB isolates these major selection criteria were resistance to low $\mathrm{pH}$ and tolerance against bile salt.

\subsubsection{Tolerance to Acidic $\mathrm{pH}$ Values}

$\mathrm{LAB}$ isolates were grown in MRS broth at $37^{\circ} \mathrm{C}$ overnight, then sub-cultured into fresh MRS broth and incubated for another $24 \mathrm{~h}$. The cultures were centrifuged at $5000 \mathrm{rpm}$ for $10 \mathrm{~min}$ at $4^{\circ} \mathrm{C}$ (Eppendorf, centrifuge $5804 \mathrm{R}$ ). The pellets were washed in sterile phosphate-buffer saline (PBS) pH 7.2 and re-suspended in PBS. PBS was modified to $\mathrm{pH} 2$ with 1 $\mathrm{M} \mathrm{HCl}$. Each LAB isolates were inoculated into the $\mathrm{pH}$ adjusted PBS at ratio 1:100 $(\mu \mathrm{l})$. Growth of LAB was monitored hourly for $3 \mathrm{~h}$ by measuring absorbance at $560 \mathrm{~nm}$ using spectrophotometer (BioTek, USA) and spread plated on MRS agar incubated at $37^{\circ} \mathrm{C}$ for $24 \mathrm{~h}$, anaerobically [5]. Each test was carried out in triplicate.

\subsubsection{Bile Tolerance}

The tolerance of LAB isolates oxbile was tested using sterile flat-bottom 96-well microtiter plate (Falcon, Becton
Dickinson and Company, Frankin Lakes, NJ, USA). MRS broth (Oxoid CM0359) with $0.3 \%$ w/v of bile (Sigma) was prepared, and $150 \mu \mathrm{L}$ was added to each well inoculated with $30 \mu \mathrm{L}$ of overnight culture previously diluted $1 / 1000$ in the same broth. Microplate was incubated anaerobically at $37^{\circ} \mathrm{C}$ for $24 \mathrm{~h}$. Optical densities (OD) were read at $600 \mathrm{~nm}$ using spectrophotometer (Eppendorf Asia Pacific Sdn. Bhd) [5]. Each test was carried out in triplicate.

\subsection{Determination of Antibacterial Activity}

\subsubsection{Pathogens Used to Study Antimicrobial Activity of the} Isolated $\mathbf{L A B}$

The target bacteria (Escherichia coli ATCC 25922, Bacillus subtilis ATCC21332, Staphylococcus aureus ATCC 25923 and Salmonella typhimurium ATCC 13311) was used for screening of antimicrobial activity.

\subsubsection{Antimicrobial Activity of LAB Isolates Using Dual Agar Overlay Method}

Antimicrobial activity of six LAB isolates was determined against target bacteria using the dual agar overlay method as described by [1]. LAB was inoculated in spot on MRS agar plates and grown at $30^{\circ} \mathrm{C}$ for $24 \mathrm{~h}$ in anaerobic jars. The plates were overlaid with $15 \mathrm{ml}$ of nutrient agar containing the target bacteria with $10^{6} \mathrm{CFU} / \mathrm{ml}$. After $24 \mathrm{~h}$ of aerobic incubation at $30^{\circ} \mathrm{C}$, the diameter of inhibition zone was measured. The tests were done in duplicate and the mean of diameter of inhibitory zones was taken.

\subsubsection{Antibacterial Activity of LAB Supernatant Using Microtiter Plates}

Cell free supernatant was obtained from centrifugation (6500 x g for $15 \mathrm{~min}$ ) and filtration of overnight MRS broth inoculated with $\mathrm{LAB}$ isolates incubated at $30^{\circ} \mathrm{C} 24 \mathrm{~h}$ anaerobically. Nutrient broth (Oxoid) was prepared and mixed with the target bacteria containing $10^{4} \mathrm{CFU} / \mathrm{ml} .100 \mu \mathrm{l}$ of the supernatant and target bacteria were pipetted into the wells of microtiter plates. $200 \mu 1$ of target bacteria in nutrient broth without the addition of supernatant was used as positive control. All microtiter plates were incubated at $30^{\circ} \mathrm{C}$ for 24, 48, and $72 \mathrm{~h}$. Bacterial growth was monitored at $\mathrm{OD}_{560}$ of MRS broth using BioTek ELx800 ELISA reader. The analysis was carried out in duplicates and the mean of optical density was taken. The percentage growth of target bacteria was calculated using the formula established by [7]: [OD $560 \mathrm{~nm}$ with bacteria/supernatant after incubation OD560 nm of MRS broth with the bacteria at time 0h] / [OD560 nm of MRS broth with the bacteria at time 0h] $\mathrm{x}$ 100 .

\section{Results}

\subsection{Isolation of Lactic Acid Bacteria (LAB)}

Six from twenty five $\mathrm{LAB}$ isolated from human breast milk showed clear zone on modified $\mathrm{MRS}-\mathrm{CaCO}_{3}$ agar, catalase negative and Gram positive and were considered as LAB (Table). 
Table 1. Phenotypic Characteristics of LAB Isolated.

\begin{tabular}{llll}
\hline LAB Codes & Catalase reaction & Gram reaction & Cell morphology \\
\hline HM1 & - & + & Short rod \\
HM2 & - & + & Short rod \\
HM3 & - & + & Cocci \\
HM4 & - & + & Short rod \\
HM5 & - & + & Short rod \\
HM6 & - & + & Short rod, cluster \\
\hline
\end{tabular}

$(+)$ positive, $(-)$ negative reactions

\subsection{Probiotic Properties of LAB Isolates}

\subsubsection{Tolerance to Acidic pH Values}

The viable counts and survival rates of the selected six LAB isolates are shown in Table 2. All tested strains showed resistance to low $\mathrm{pH}$. The viable counts of all strains were found to be $>10^{6} \mathrm{CFU} / \mathrm{ml}$ after incubation at $\mathrm{pH} 2.0,37^{\circ} \mathrm{C}$ for $3 \mathrm{~h}$. Overall, all strains showed higher resistance to low $\mathrm{pH}$ at the range from $88.3 \%$ to $68.0 \%$. The different survival rates of LAB strains suggested that the survival activity was strainspecific.
Table 2. Survival of pH-stressed LAB isolates in MRS Incubated at $37^{\circ} \mathrm{C}^{a b}$.

\begin{tabular}{llllll}
\hline $\begin{array}{l}\text { LAB } \\
\text { isolates }\end{array}$ & $\mathbf{0}$ & $\mathbf{1}$ & $\mathbf{2}$ & $\mathbf{3}$ & $\begin{array}{l}\text { Survival } \\
\text { percentage } \\
\text { (\%) }\end{array}$ \\
\hline HM1 & $8.29 \pm 0.10$ & $7.80 \pm 0.15$ & $7.04 \pm 0.12$ & $6.32 \pm 0.22$ & 76.2 \\
HM2 & $8.31 \pm 0.43$ & $7.91 \pm 0.32$ & $7.21 \pm 0.10$ & $6.37 \pm 0.20$ & 76.6 \\
HM3 & $8.17 \pm 0.61$ & $7.60 \pm 0.13$ & $7.36 \pm 0.09$ & $7.22 \pm 0.44$ & 88.3 \\
HM4 & $8.55 \pm 0.21$ & $7.86 \pm 0.19$ & $7.51 \pm 0.67$ & $7.33 \pm 0.31$ & 85.7 \\
HM5 & $8.41 \pm 0.55$ & $7.58 \pm 0.32$ & $6.60 \pm 0.11$ & $5.72 \pm 0.64$ & 68.0 \\
HM6 & $8.37 \pm 0.90$ & $8.03 \pm 0.33$ & $7.85 \pm 0.12$ & $6.48 \pm 0.24$ & 77.4 \\
\hline
\end{tabular}

${ }^{\mathrm{a}}$ Growth $\mathrm{LAB}$ was monitored at $\mathrm{OD}_{560} \mathrm{~nm}$ after $24 \mathrm{~h}$ incubation at $37^{\circ} \mathrm{C}$.

${ }^{\mathrm{b}} \mathrm{pH}$ of MRS broth was adjusted with $1 \mathrm{M} \mathrm{HCl}$.

\subsubsection{Bile Tolerance}

The growth capabilities of six previously selected strains under $0.3 \%$ bile salt condition was determined by absorbance at $600 \mathrm{~nm}$ after $3 \mathrm{~h}$ incubation at $37^{\circ} \mathrm{C}$ as shown in Table 3. The results of determination of viable counts and survival rates showed that all tested strains were found to be resistant to bile salt at the range from rates $69.8 \%$ to $85.0 \%$. The HM1 isolate demonstrated the highest bile salt resistance followed by HM3 isolate with $85.0 \%$ and $81.4 \%$, respectively.

Table 3. Survival of LAB isolates in MRS Broth with $0.3 \%$ of Bile Incubated at $37^{\circ} \mathrm{C}^{a}$.

\begin{tabular}{lllll}
\hline \multirow{2}{*}{ LAB isolates } & Time (h2) & & \\
\cline { 2 - 5 } & $\mathbf{0}$ & $\mathbf{1}$ & $\mathbf{2}$ & $\mathbf{3}$ \\
\hline HM1 & $8.05 \pm 0.22$ & $7.63 \pm 0.21$ & $7.04 \pm 0.12$ & $6.85 \pm 0.07$ \\
HM2 & $7.98 \pm 0.32$ & $6.77 \pm 0.40$ & $6.54 \pm 0.15$ & $5.69 \pm 0.09$ \\
HM3 & $8.25 \pm 0.11$ & $6.81 \pm 0.13$ & $6.45 \pm 0.09$ & $5.82 \pm 0.52$ \\
HM4 & $8.41 \pm 0.08$ & $7.98 \pm 0.07$ & $7.24 \pm 0.21$ & $6.85 \pm 0.03$ \\
HM5 & $8.19 \pm 0.25$ & $7.51 \pm 0.02$ & $7.29 \pm 0.01$ & $6.49 \pm 0.34$ \\
HM6 & $8.51 \pm 0.90$ & $7.45 \pm 0.13$ & $6.99 \pm 0.05$ & 6.609 \\
\hline
\end{tabular}

${ }^{a}$ Growth was monitored at $\mathrm{OD}_{560} \mathrm{~nm}$.

\subsection{Determination of Antibacterial Activity}

\subsubsection{Antimicrobial Activity of LAB Isolates Using Dual Agar Overlay Method}

All the six LAB isolates showed different inhibitory activities against the target bacteria by the dual agar overlay method. $S$. aureus was greatly inhibited by all LAB isolates as shown by the inhibitory zone greater than $25 \mathrm{~mm}$ while $B$. subtilis was inhibited but to a lesser inhibitory effects (Table 4). The LAB-HM6 isolate showed the highest inhibitory activity $(32.0 \mathrm{~mm})$ against $S$. aureus followed by LAB-HM5 and LAB-HM4 (30.3 mm), then LAB-MH1 (29.3 $\mathrm{mm})$ against $S$. typhimurium.

Table 4. Growth Inhibition Zone of Target Bacteria by LAB Isolated by Dual Agar Overlay Method ${ }^{a}$.

\begin{tabular}{|c|c|c|c|c|c|c|}
\hline \multirow{2}{*}{ Target bacteria } & \multicolumn{6}{|c|}{ LAB strains } \\
\hline & HM1 & HM2 & HM3 & HM4 & HM5 & HM6 \\
\hline E. coli & $17.5 \pm 0.7$ & $7.5 \pm 3.5$ & $12.5 \pm 0.7$ & $16.2 \pm 0.8$ & $14 \pm 2.8$ & $18 \pm 2.8$ \\
\hline B. subtilis & $16.5 \pm 0.7$ & $11.5 \pm 0.7$ & $16.5 \pm 2.1$ & $16.5 \pm 0.7$ & $13.5 \pm 0.7$ & $18.5 \pm 3.5$ \\
\hline S. aureus & $28.0 \pm 0.2$ & $25.0 \pm 0.2$ & $26.0 \pm 0.2$ & $28.0 \pm 0.2$ & $30.0 \pm 2.8$ & $32.0 \pm 0.2$ \\
\hline S. typhimurium & $29.3 \pm 4.2$ & $23.2 \pm 0.3$ & $25 \pm 2.8$ & $30.3 \pm 0.6$ & $30.3 \pm 1.4$ & $23.5 \pm 0.7$ \\
\hline
\end{tabular}

${ }^{\text {a }}$ Diameter of growth inhibitory zone was measured in mm after $24 \mathrm{~h}$ incubation at $30^{\circ} \mathrm{C}$

\subsubsection{Antibacterial Activity of LAB Supernatant Using Microtiter Plates}

Percentage growth of target bacteria were reduced in the range of 40 to $80 \%$ by the supernatant of all $\mathrm{LAB}$ isolates compared to control within $24 \mathrm{~h}$ incubation (Table 5). Supernatant LAB-HM5 caused complete inhibition of all target bacteria, LAB-HM3 inhibited $S$. typhimurium and $B$. subtilis, and LAB-HM5 also inhibited the growth of $S$. aureus during $72 \mathrm{~h}$ incubation. However, some LAB supernatant allowed growth of the target bacteria as shown by LAB-HM2 against $S$. aureus after $24 \mathrm{~h}$ incubation and LAB-HM3 against $S$. typhimurium after $48 \mathrm{~h}$ incubation. 
Table 5. Percentage growth of target bacteria in the presence of LAB supernatant in microtiter plates incubated at $30^{\circ} \mathrm{C}$ for $72 \mathrm{~h}^{a}$.

\begin{tabular}{|c|c|c|c|c|c|c|c|c|}
\hline \multirow{2}{*}{ Target bacteria } & \multirow{2}{*}{ Time (h) } & \multicolumn{6}{|c|}{ LAB strains } & \multirow{2}{*}{ Control } \\
\hline & & HM1 & HM2 & HM3 & HM4 & HM5 & HM6 & \\
\hline \multirow{3}{*}{ S. aureus } & 24 & 24.51 & 0.30 & 3.51 & 2.49 & NG & 2.01 & 77.04 \\
\hline & 48 & 5.06 & NG & 2.20 & 0.24 & 7.17 & 2.41 & 120.75 \\
\hline & 72 & 9.51 & 1.71 & NG & NG & 81.49 & 2.81 & 151.57 \\
\hline \multirow{3}{*}{ S. typhimurium } & 24 & 3.74 & 6.79 & 9.14 & NG & 6.75 & NG & 49.70 \\
\hline & 48 & 4.44 & 7.22 & 6.38 & NG & 24.60 & NG & 76.16 \\
\hline & 72 & 5.49 & 6.91 & 7.73 & NG & 17.68 & 5.11 & 98.68 \\
\hline \multirow{3}{*}{ B. subtilis } & 24 & 4.41 & 10.11 & 8.94 & 7.52 & 8.22 & NG & 88.58 \\
\hline & 48 & 1.33 & 2.81 & 5.90 & NG & 25.21 & NG & 129.30 \\
\hline & 72 & 3.62 & 26.22 & 7.22 & NG & 18.65 & $\mathrm{NG}$ & 157.75 \\
\hline
\end{tabular}

${ }^{\text {a }}$ Growth was measured as OD at $560 \mathrm{~nm}, \mathrm{NG}$ : No growth

\section{Discussion}

In this study, six LAB strains isolated from human breast milk were investigated for their probiotic properties. Tolerance to acidic condition is the most commonly used method to detect the viability and activity of probiotic bacteria in the small intestine and stomach. According to a previous study [3, 10]. The survival rate at $\mathrm{pH} 2$ is considered as optimal acid tolerance for selected probiotic strains. All strains from this study were able to tolerance $\mathrm{pH} 2.0$ with survival percentage of more than $68.0 \%$, and therefore they can be considered as acid-tolerant LAB strains.

Tolerance to bile salts is usually considered a basic property for LAB strains to survival in the small intestine. in this study, all tested strains indicated a proportion of growth above $69.8 \%$ in the present bile salt $0.3 \%$, which demonstrated good bile salt tolerance. These results were consistent with previous study [3, 9, 11]. To further investigate the safety and functional characteristic of these strains as probiotic, tests were conducted to assess their antimicrobial activity.

As a potential probiotic, antimicrobial activity is one important property to avoid gastrointestinal infection [4]. In the present study, both the cells and supernatants of six selected LAB isolated from human breast milk were screened for antimicrobial activity. The antimicrobial activity in this study was carried out longer than $24 \mathrm{~h}$ than that normally carried by other researchers [8] to determine the bacteriostatic or bactericidal effect. $L$. acidophilus supernatant showed bactericidal effect against the target bacteria especially $S$. aureus. LAB-HM5 and LAB-HM6 showed good inhibition against the growth of $S$. aureus with diameter of inhibition zone between 30 and $32 \mathrm{~mm}$. Similarly, [6] observed that L. acidophilus isolated from stock culture of yogurt in Iraq showed antimicrobial activity against Gram-positive bacteria; S. aureus, S. epidermis and bacilli that cause burn wound infections. Earlier reports showed that LAB isolated from human intestine have antimicrobial activity against a wide range of Gram-negative and Gram-positive pathogens in vitro and in vivo $[3,10,1]$.

The ability to inhibit the pathogens of tested strains could be explaind by the production of antimicrobial compounds. According to the study of [3], the antimicrobial effect of $\mathrm{LAB}$ is due the production of metabolites, such as lactic acid, acetic acid, diacetyl, fatty acids, aldehydes bacteriocins and other compound, among which, lactic acid, acetic acid and bacteriocins are most powerful antimicrobial agents and are production of the probiotics. This study suggested that many compounds are responsible for the antimicrobial activity and can not be attributed to one or to main compounds present in breast milk human.

\section{Conclusion}

In conclusion, this study observed that LAB from human breast milk have probiotic properties with varying antibacterial activity against human pathogenic strains. The S. aureus was readily inhibited by either the cells or cell-free supernatants of all the LAB isolates. Additionally, antimicrobial compounds produced by these LABs may play important role in enhancing the antimicrobial properties and the medicinal benefit. These strains could be potentially used in functional food and health products. This work further supports that breast milk human could be used as antibacterial agent.

\section{Acknowledgements}

The author would like to thank the Department Botany, Faculty of Science, Zawia University for their support.

\section{References}

[1] Adeniyi, B. A., Adetoye, A. and Ayeni, F. A. (2015). Antibacterial Activity of Lactic Acid Bacteria Isolated from Cow Faeces Against Potantial Enteric Pathogens. Afri. Health. Sci., 15 (3): 888-895.

[2] Aween, M., Hassan, Z. and Belal, M. (2012). Evaluation on Antibacterial Activity of Lactobacillus acidophilus Strains Isolated from Honey. American Journal of Applied Sciences, 9 (24): 807-817.

[3] Azat, R., Liu, Y., Li, W., Kayir, A., Lin, D., Zhou, W. and Zheng, X. (2016). Probiotic Properties of Lactic Acid Bacteria Isolated from Traditionally Fermented Xinjiang cheese. J. Zhejiang. Univ-Sci B (Biomed \& Biotegnol), 17 (8): 597-609.

[4] Kanmani, P., Satish Kumar, R. and Yuvaraj, N. (2013). Probiotics and its Functionally valuable products a review. Crit. Rev. Food Sci. Nutr., 53 (6): 641-658. 
[5] Khaedr, E. E. (2006). Microbial and Processing Criteria for Production of Probiotics: A review. Food Technol. Biotechnol., 44: 371-379.

[6] Mohammed, S. J. (2010). Therapeutic efficacy of Lactobacillus acidophilus against bacterial isolates from burn wounds. North American Journal of Medical Sciences, 2: $1947-2714$

[7] Muhialdin, B. J., Hassan, Z., Sadon, S. K. Zulkifli, N. A. and Azfar, A. A. (2011a). Effect of $\mathrm{pH}$ and heat treatment on antifungal activity of Lactobacillus fermentum Te007, Lactobacillus pentosus G004 and Pediococcus pentosaceus Te010. Innovative Romanian Food Biotechnology, 8: 41-53.

[8] Oliveira, R. B. P., Oliveira, A. L. and Glória, M. B. A. (2008). Screening of lactic acid bacteria from vacuum packaged beef for antimicrobial activity. Brazilian Journal of Microbiology, 39: $368-374$.
[9] Shehata, M. G., El-Sohaimy, S. A., El-Sahn, M. A. and Youssef, M. M. (2016). Screening of isolated Potential Probiotic Lactic Acid Bacteria for Cholesterol Lowering Property and Bile Salt Hydrolase Activity. Annals Agricultural Science, 61 (1): 65-75.

[10] Shokryazdan, P., Sio, C., Kalavathy, R., Liang, J., Alitheen, N., Jahromy, M. and Ho, Y. (2014). Probiotic Potential of Lactobacillus Strains with Antimicrobial Activity Against Some Human Pathogenic Strains. BioMed Research International, 14: 1-16.

[11] Turchi, B., Mancini, S. and Fratini, F. (2013). Preliminary Evaluation Probiotic Potential of Lactobacillus plantarum Strains Isolated from Italian Food Products. World J. Microbiol. Biotechnol., 29 (10): 1913-1922. 